\title{
Induced Hypothermia Does Not Harm Hemodynamics after Polytrauma: A Porcine Model
}

\author{
Matthias Weuster, ${ }^{1}$ Philipp Mommsen, ${ }^{2}$ Roman Pfeifer, ${ }^{3}$ \\ Juliane Mohr, ${ }^{4,5}$ Steffen Ruchholtz, ${ }^{4}$ Sascha Flohé, ${ }^{6}$ Matthias Fröhlich, ${ }^{3,7}$ Claudia Keibl, \\ Andreas Seekamp, ${ }^{1}$ Martijn van Griensven, ${ }^{8,9}$ and Ingo Witte ${ }^{6}$
}

\author{
${ }^{1}$ Department of Trauma Surgery, University of Schleswig-Holstein, 24105 Kiel, Germany \\ ${ }^{2}$ Department of Trauma Surgery, Hannover Medical School, 30625 Hannover, Germany \\ ${ }^{3}$ Department of Trauma Surgery, University of Aachen, 52074 Aachen, Germany \\ ${ }^{4}$ Department of Trauma Surgery, University of Marburg-Giessen, 35043 Marburg, Germany \\ ${ }^{5}$ Department of Trauma Surgery, University of Magdeburg, 39120 Magdeburg, Germany \\ ${ }^{6}$ Department of Trauma Surgery, University of Düsseldorf, 40225 Düsseldorf, Germany \\ ${ }^{7}$ Department of Trauma Surgery, University of Witten-Herdecke, 51109 Köln-Merheim, Germany \\ ${ }^{8}$ Ludwig Boltzmann Institute for Experimental and Clinical Traumatology, 1200 Vienna, Austria \\ ${ }^{9}$ Department of Experimental Trauma Surgery, Klinikum Rechts der Isar, Technical University Munich, 81675 Munich, Germany
}

Correspondence should be addressed to Matthias Weuster; matthias.weuster@uksh.de

Received 3 October 2014; Revised 5 May 2015; Accepted 5 May 2015

Academic Editor: Wilco de Jager

Copyright ( 2015 Matthias Weuster et al. This is an open access article distributed under the Creative Commons Attribution License, which permits unrestricted use, distribution, and reproduction in any medium, provided the original work is properly cited.

Background. The deterioration of hemodynamics instantly endangers the patients' life after polytrauma. As accidental hypothermia frequently occurs in polytrauma, therapeutic hypothermia still displays an ambivalent role as the impact on the cardiopulmonary function is not yet fully understood. Methods. We have previously established a porcine polytrauma model including blunt chest trauma, penetrating abdominal trauma, and hemorrhagic shock. Therapeutic hypothermia $\left(34^{\circ} \mathrm{C}\right)$ was induced for 3 hours. We documented cardiovascular parameters and basic respiratory parameters. Pigs were euthanized after 15.5 hours. Results. Our polytrauma porcine model displayed sufficient trauma impact. Resuscitation showed adequate restoration of hemodynamics. Induced hypothermia had neither harmful nor major positive effects on the animals' hemodynamics. Though heart rate significantly decreased and mixed venous oxygen saturation significantly increased during therapeutic hypothermia. Mean arterial blood pressure, central venous pressure, pulmonary arterial pressure, and wedge pressure showed no significant differences comparing normothermic trauma and hypothermic trauma pigs during hypothermia. Conclusions. Induced hypothermia after polytrauma is feasible. No major harmful effects on hemodynamics were observed. Therapeutic hypothermia revealed hints for tissue protective impact. But the chosen length for therapeutic hypothermia was too short. Nevertheless, therapeutic hypothermia might be a useful tool for intensive care after polytrauma. Future studies should extend therapeutic hypothermia.

\section{Introduction}

Therapeutic hypothermia (TH) [1] has gained increasing popularity over the last years. Widely used in elective fields of surgery [2,3], TH takes an important role in tissue protection and facilitates a reduction of the metabolic rate [4]. Nevertheless, its positive effect is still controversially discussed as populations in cardiac arrest and traumatic brain injury studies were not quite comparable $[1,5-7]$. Furthermore, hypothermia plays an ambivalent role in polytrauma patients as many suffer from accidental hypothermia $(\mathrm{AH})$. AH can be distinguished by its degree Celsius $\left({ }^{\circ} \mathrm{C}\right)$ as mild $\left(33-36^{\circ} \mathrm{C}\right)$, moderate $\left(28-32.9^{\circ} \mathrm{C}\right)$, deep $\left(11-27.9^{\circ} \mathrm{C}\right)$, profound $\left(6-10.9^{\circ} \mathrm{C}\right)$, and ultraprofound $\left(<6^{\circ} \mathrm{C}\right)$ [8]. The exposure to cold environment and forced volume management induces a decrease in body core temperature. Following 
ATLS guidelines it is indispensable to avoid the lethal triad of accidental hypothermia, acidosis, and coagulopathy as these components aggravate patients' outcome [9]. If temperatures decline below $34^{\circ} \mathrm{C}$ coagulation disorders occur with reversible thrombocytopenia and thrombocytopathy. Plasmatic coagulopathy occurs below $33^{\circ} \mathrm{C}$ with disorders in thrombin and fibrin function [10]. The development of coagulopathy is supported under circumstances of increased heat loss, hemorrhage, and uncontrolled fluid management in trauma scenarios. Unfortunately, major complications appear in the clinical course with high mortalities correlating with hemorrhagic shock after blunt chest and penetrating abdominal trauma [11-13]. Studies have proven that hypovolemia alone is sufficient enough to cause remote organ damage potentiated by insufficient tissue oxygenation [14]. Therefore, strategies in emergency care medicine emphasize the golden hour of shock in which tissue perfusion and oxygenation need to be improved; here invasive devices for hemodynamic monitoring such as the pulmonary artery catheter have been used for goal-directed resuscitation [15]. Early detection of cardiac failure still belongs to the most challenging aspects in shock management [16]. Considering these circumstances, TH might improve organ functions after polytrauma. Superior effects of TH are still unknown.

The aim of our investigation was to analyze the hemodynamics due to therapeutic hypothermia after polytrauma and resuscitation in a porcine model. Cardiovascular parameters were documented in order to detect benefits and harmful impact of TH. We hypothesized that hemodynamics after polytrauma could benefit from mild therapeutic hypothermia. TH might be an important tool in trauma care as used in other fields of emergency care $[2,17,18]$.

\section{Methods and Material}

2.1. Animal Care. This study was approved by the regional animal welfare Committee of Vienna, Austria, confirming the guidelines of the National Institutes of Health for the use of experimental animals. The experiment was performed in $n=40$ male pigs (German domestic pigs, Muenichstal) aged 12 to 16 weeks and weighing $30 \pm 3 \mathrm{~kg}[14,19,20]$. Water was available ad libitum and the animals were fasted overnight. 20 pigs were assigned to a sham group with either normothermic $(n=10)$ or hypothermic conditions $(n=10)$ only receiving anesthesia and placement of arterial, venous, and urinary lines. 20 pigs were analyzed in a trauma group with blunt chest trauma, liver laceration, and hemorrhagic shock with either normothermic $(n=10)$ or hypothermic conditions $(n=10)$ after resuscitation. All experimental procedures were conducted in deep anesthesia. All animals were sacrificed 15.5 hours by bolus infusion of potassium chloride.

2.2. Anesthesia. The animals were kept in a supine position. Anesthesia was induced with an intramuscular application of zoletil mixture (xylazine $146 \mathrm{mg}$, ketamine $125 \mathrm{mg}$, butorphanol $25 \mathrm{mg}$, tiletamine $50 \mathrm{mg}$, and zolazepam $50 \mathrm{mg}$ ) in a dose rate of $1 \mathrm{~mL} / 15 \mathrm{~kg} / \mathrm{pig}$. After endotracheal intubation and during preparation, anesthesia was performed using isoflurane $1.5 \%$ with rocuronium $(5 \mathrm{mg} / \mathrm{kg} / \mathrm{h})$ and sufentanil $(0.008 \mathrm{mg} / \mathrm{kg} / \mathrm{h})$ intravenously via ear vein access. From baseline (BL) on, anesthesia was maintained for the entire study period as total intravenous anesthesia with midazolam $(0.8 \mathrm{mg} / \mathrm{kg} / \mathrm{h})$, rocuronium $(5 \mathrm{mg} / \mathrm{kg} / \mathrm{h})$, and sufentanil $(0.008 \mathrm{mg} / \mathrm{kg} / \mathrm{h})$. This medication was chosen in order to prevent any diminution in cardiopulmonary functions like a decrease of mean arterial pressure (MAP) as effectuated by inhalation anesthetics [21]. Liquids were given for all animals during the protocol per crystalloids (Ringer, 309 mosmol/L, Fresenius Kabi GmbH, Graz, Austria) in a rate of $10 \mathrm{~mL} / \mathrm{kg}$ bodyweight/hour. During the whole study period, oxygenation and ventilation were continuously monitored and adapted to obtain physiologic levels with a pressure-volume-controlled setting in a ventilator (Draeger, Primus, Danvers, MA, USA). $\mathrm{A} \mathrm{FiO}_{2}$ of $30 \%$, a tidal volume of $10 \mathrm{~mL} / \mathrm{kg} /$ bodyweight, 20 breaths $/ \mathrm{min}$, a PEEP of $3 \mathrm{mbar}$, $\mathrm{paCO}_{2}$ of $35-45 \mathrm{mmHg}$, and end-tidal $\mathrm{CO}_{2}$ of $4.5-5.5 \%$ were set.

2.3. Preparation of the Animals. Preparations were performed in an aseptic technique. Saline-filled catheters were placed intraluminally by preparing the following arteries and veins: left carotidal artery for arterial line (B. Braun Perfusor Line, Melsungen, Germany), left external jugular vein for drug and medical substitution by applying a 9FR-central venous catheter (Arrow Int. Reading, PA, USA), and right external jugular vein by applying a Swan-Ganz catheter for drug and medical substitution as well as measuring hemodynamic parameters (Swan \& Ganz Combo, Heparin Coated, Edwards Lifesciences, Irvine, CA, USA). The right arteria femoralis was provided with an arterial line for managing hemorrhagic shock (B. Braun Perfusor Line, Melsungen, Germany) and the right vena femoralis with the Icy catheter (ZOLL Circulation, Inc., Sunnyvale, CA, USA) for inducing hypothermia. The urinary output was monitored after preparation of the bladder inserting a suprapubic urinary catheter (Cystofix, B. Braun, Melsungen, Germany).

2.4. Polytrauma. Polytrauma was induced at baseline (BL) consisting of blunt chest trauma, penetrating abdominal injury, and hemorrhagic shock. Shock/trauma (S) was maintained over a period of 90 minutes. Resuscitation (R) followed for 60 minutes. Measurements were performed at certain points of time until the end at 15.5 hours (Figure 4). Laboratory and blood gas-parameters hemoglobin ( $\mathrm{Hb}$ in $\mathrm{g} / \mathrm{dL}$ ), arterial $\mathrm{pH}$, base excess (BE), $\mathrm{HCO}^{3-}$, lactate (LC), and glycemia (Gluc) were analyzed (ABL 800 Flex, Drott, Wiener Neudorf, Austria). Respiratory parameters were adjusted if necessary to keep them on a physiologic level at $\mathrm{BL}$. $\mathrm{FiO}_{2}$ was reduced from $30 \%$ to $21 \%$ in sham and in trauma animals just before BL in order to mimic normal physiological and equal conditions at BL. RF was maintained at $22.8 \pm 3.0 / \mathrm{min}$ in sham and $22.1 \pm 3.8 / \mathrm{min}$ in trauma animals at BL. At first, blunt chest trauma was performed by a bolt shot on a lead panel of $1 \mathrm{~cm}$ thickness to the right dorsal, lower chest using cattle killing cartridges $(9 \times 17$, Dynamit Nobel AG, Troisdorf, Germany). The shot was applied while the lungs of the animals were semideflated. Subsequently, laparotomy 
was done by exploration and by two incisions in the right upper liver lobe using a custom-made sharp four-edged scalpel. Then uncontrolled bleeding followed for 30 seconds, afterwards liver packing with 5 sterile packs of the same size. Laceration-associated bleeding was assessed macroscopically every 30 minutes. There were no surgical interventions to stop bleeding after laceration. Pressure-controlled hemorrhagic shock was induced by withdrawing blood to a mean arterial blood pressure (MAP) of $30 \pm 5 \mathrm{mmHg}$ from the right femoral artery with a maximum of $45 \%$ of the total blood volume. Mean blood loss was $880 \pm 133 \mathrm{~mL}$ in normothermic trauma animals and $829 \pm 162 \mathrm{~mL}$ in hypothermic trauma animals. Hemorrhagic shock was maintained for 90 minutes. Shed blood was abolished. There were no surgical interventions to stop the bleeding.

2.5. Resuscitation. Resuscitation began and lasted for 60 minutes. It followed straight after the period of shock. We approached a mean arterial pressure (MAP in $\mathrm{mmHg}$ ) of $60 \mathrm{mmHg}$ and a heart rate of less than 150/min in order to conduct a goal directed therapy only by volume management. Thus, we used colloids (HES 130/4, 6\%, Voluven, $308 \mathrm{mosml} / \mathrm{L}$, Fresenius Kabi GmbH, Graz, Austria) and crystalloids (Ringer, 309 mosmol/L, Fresenius Kabi GmbH, Graz, Austria) for fluid resuscitation with four times the shed blood in a relation of 1:8 (12.5\% hydroxyethyl starch "HES" and $87.5 \%$ Ringer) [14, 22]. Sham animals only received crystalloids in a rate of $10 \mathrm{~mL} / \mathrm{kg}$ bodyweight/hour. Fluid balance was documented. There was no adjunctive medication for resuscitation. Pigs were constantly evaluated and if required treated by current standards of emergency medicine and trauma surgery, that is, Acute Trauma Life Support (ATLS) and European Resuscitation Council (ERC) from 2010 [17, 23]. These protocols allow standard techniques such as inserting chest tubes in case of pneumothoraces and draining blood from cardiac tamponade by needle punctures. Vasopressors, inotropes, and dilators were only applied for life-threatening events such as acute hypotension, ventricular fibrillation, and cardiac arrest.

2.6. Normothermia and Hypothermia. Body core temperature (in Celsius ${ }^{\circ} \mathrm{C}$ ) was gained continuously by anal wire thermometer (Draeger, Infinity Delta, Danvers, MA, USA). Therapeutic hypothermia (TH) was induced after resuscitation by Icy catheter. A triple infusion lumen was placed in the right vena femoralis and connected to a CoolGard3000/Thermogard XP system (ZOLL Circulation, Inc., Sunnyvale, CA, USA). We targeted a mild hypothermic temperature at $34.3 \pm 0.2^{\circ} \mathrm{C}$ as the porcine physiologic temperature is higher than in humans anyway $\left(38^{\circ}\right.$ and $\left.39.5^{\circ} \mathrm{C}\right)[24,25]$. It took 90 minutes to restore a physiologic temperature of $37^{\circ} \mathrm{C}$ which was maintained until the end of protocol (Figure 4). Generally, the entire protocol was 15.5 hours long with a short period of 3 hours for TH due to ethical agreements of our model and due to logistical settings at site. We were not allowed to waken the animals afterwards. Therefore we had to shorten the phase of $\mathrm{TH}$ within the intensive care phase.
2.7. Hemodynamics. Hemodynamic parameters were continuously monitored with noninvasive and invasive methods. A standard electrocardiogram (ECG) monitoring cardiac rhythm, heart rate (HR in $1 / \mathrm{min}$ ), and invasive mean arterial blood pressure (MAP in $\mathrm{mmHg}$ ) were deducted. A SwanGanz (continuous cardiac output thermodilution/mixed venous oxygen saturation, Edwards Lifesciences, Vigilance, Irvine, CA, USA) was inserted to observe pulmonary hemodynamic pressures, that is, central venous pressure (CVP in $\mathrm{mmHg}$ ), measurement of mixed venous oxygen saturation $\left(\mathrm{SvO}_{2}\right.$ in \%), and cardiac output ( $\mathrm{CO}$ in $\left.1 / \mathrm{min}\right)$. $\mathrm{CO}$ and $\mathrm{SvO}_{2}$ were displayed on a Vigilance monitor. Additional measurements involved stroke volume ( $\mathrm{SV}$ in $\mathrm{mL}$ ), pulmonary artery pressure (PAP systolic, diastolic, and mean in $\mathrm{mm} \mathrm{Hg}$ ), and balloon inflation for wedge pressure (WP in $\mathrm{mmHg}$ ). PAP was documented 5 min after blunt chest shot. Further total peripheral resistance (TPR in dyn $* \mathrm{~s} * \mathrm{~cm}^{-5}$ ) was documented. Catheter placements and lines were controlled regularly for free air and thrombotic material.

2.8. Statistics. The statistical evaluation was carried out with Prism, Version 5.0a (GraphPad Software, Inc., La Jolla, CA, USA). Measurements are presented as means, standard error of the mean with maximum and minimum. The size of each group was $n=10$. Unpaired $t$-test was calculated when comparing two values between sham and trauma animals. One-way ANOVA and Tukey's multiple comparison tests were performed. The significance was calculated as $P<0.05$.

\section{Results}

3.1. Temperature Control (Figure 1). Both normothermic and hypothermic sham and trauma animals survived the procedures. Normothermic pigs did not receive endovascular cooling. Both normothermic sham and normothermic trauma animals remained at physiologic body core temperature (Figure 1). Body core temperature of normothermic trauma animals dropped due to dilutionary effects. Although prewarmed fluids were used, temperature decreased from $38.14 \pm 0.34^{\circ} \mathrm{C}$ down to $37.2 \pm 0.29^{\circ} \mathrm{C}(P<0.05)$. There were no significant differences between hypothermic sham and hypothermic trauma animals. We did not observe any arrhythmias due to $\mathrm{TH}$. In hypothermic trauma animals temperature was $37.0 \pm 0.3^{\circ} \mathrm{C}$ at $\mathrm{BL}$; it declined to $34.3 \pm 0.2^{\circ} \mathrm{C}$ at $\mathrm{H}(P<0.05)$. Body core temperature was $38.5 \pm 0.2^{\circ} \mathrm{C}$ at the end of protocol (Figure 1).

3.2. Hemodynamics (Figures 2(a)-2(j)). Hemodynamics occurred as expected after shock (Figures 2(a)-2(i)). HR of normothermic trauma pigs increased to $216.7 \pm 11 / \mathrm{min}$ $(P<0.05)$, MAP dropped significantly to $38.5 \pm 2.7 \mathrm{mmHg}$ $(P<0.05)$, and CVP declined to $3.1 \pm 0.5 \mathrm{mmHg}(P<0.05)$ after shock $(\mathrm{S})$. $\mathrm{CO}$ declined to $2.1 \pm 0.2 \mathrm{l} / \mathrm{min}$ and $\mathrm{SvO}_{2}$ significantly dropped to $15 \pm 2 \%$ after polytrauma $(P<0.05)$. PAP reached a significant peak of $31.9 \pm 1.6 \mathrm{mmHg}$ 5 minutes due to bolt shot gun $(P<0.05)$. Volume resuscitation led to a significant improvement of these parameters in normothermic and in hypothermic trauma 


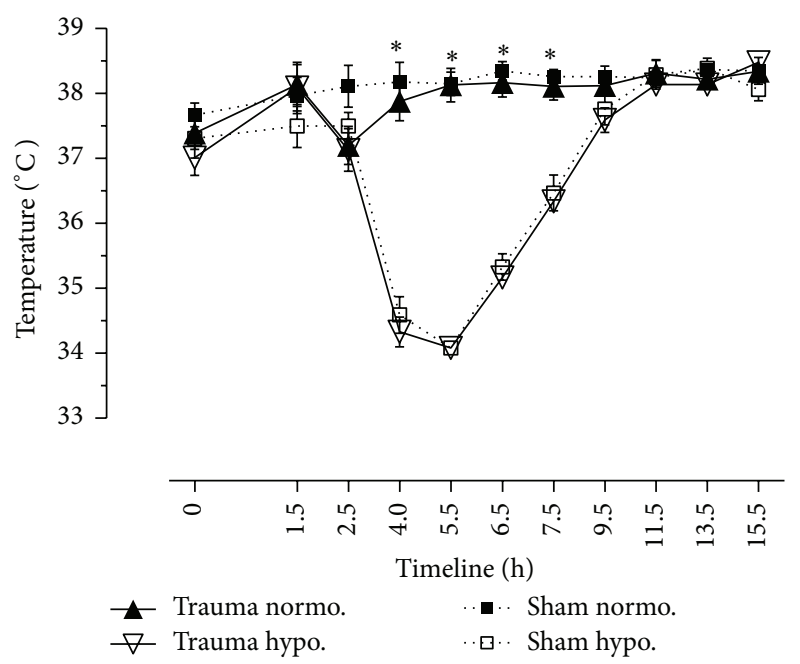

Figure 1: Temperature (in ${ }^{\circ} \mathrm{C}$ ). Temperature measured by rectal tube. Normothermic and hypothermic sham animals versus normothermic and hypothermic trauma animals. $N=40$. Timeline 15.5 hrs. Data are shown in mean and standard error of mean. ${ }^{*} P<$ 0.05 , normothermic versus hypothermic pigs during cooling phase $(4,5.5,6.5$, and $7.5 \mathrm{hrs})$.

animals. Normothermic trauma animals $(n=10)$ received $3217 \pm 259 \mathrm{~mL}$ of crystalloids and $445 \pm 66 \mathrm{~mL}$ of colloids during resuscitation. Hypothermic trauma animals $(n=10)$ received $3295 \pm 610 \mathrm{~mL}$ of crystalloids and $417 \pm 83 \mathrm{~mL}$ of colloids during resuscitation. We did not document any fluid loss in the chest. Bleeding, especially rebleeding, was not observed after laceration of the liver. Due to hypothermia, HR was significantly lower than $\mathrm{HR}$ in normothermic trauma pigs (Figure 2(a)). After rewarming, HR remained on a stable level and finished with $150 \pm 7.7 / \mathrm{min}$. TH had a significant influence on neither MAP nor CVP (Figures 2(b)-2(c)). CO remained on a lower level in hypothermic animals than in normothermic animals (Figure 2(d)). $\mathrm{SvO}_{2}$ reached significantly higher values during therapeutic cooling with $34^{\circ} \mathrm{C}(P<0.05)$. Similar effects were observed in sham animals (Figure 2(e)). The level of $\mathrm{SvO}_{2}$ significantly declined after rewarming towards the end of protocol in hypothermic trauma pigs. Values were significantly lower than in sham and in normothermic trauma pigs. TPR showed significant differences among sham and trauma animals throughout the whole protocol. Values already differed at BL between sham and trauma animals. In clinical course, TPR reached four times higher values in hypothermic animals (Figure 2(i)). Vasopressors and inotropes, that is, norepinephrine and epinephrine, were used only in a very few animals in this trauma model. Sham animals did not need catecholamine medication. Five normothermic trauma animals and one hypothermic trauma animal needed catecholamine medication. This medication was started after rewarming in all cases. Dosages were applied with either epinephrine or norepinephrine in $3 \mathrm{mg} / 50 \mathrm{~mL}$ (Figure $2(\mathrm{j})$ ).

3.3. Laboratory Parameters and Blood Gases (Figures 3(a)$3(c)$ ). Our polytrauma model with blunt chest trauma, penetrating abdominal trauma, and hemorrhagic shock caused a depletion of laboratory parameters and blood gases (Figures $3(\mathrm{a})-3(\mathrm{c}))$. Hemoglobin ( $\mathrm{Hb}$ in $\mathrm{g} / \mathrm{dL}$ ) decreased from $9.5 \pm$ $0.3 \mathrm{~g} / \mathrm{dL}$ in normothermic trauma animals and from $9.1 \pm$ $0.4 \mathrm{~g} / \mathrm{dL}$ in hypothermic trauma animals at $\mathrm{BL}$ down to $5.2 \pm 0.2 \mathrm{~g} / \mathrm{dL}$ at R. The depth of shock was displayed through decreased base excess (BE) at $-3.6 \pm 0.9 \mathrm{mmol} / \mathrm{L}$ and increased lactate (LC) at $79.4 \pm 7.4 \mathrm{mg} / \mathrm{dL}$ evaluated after trauma [14]. Physiologic arterial pH is between 7.39 and 7.45 in porcine model [26]. Both sham and trauma pigs in our study had an arterial $\mathrm{pH}$ of 7.44 at BL. It continuously decreased down to $7.25 \pm 0.03$ in normothermic trauma pigs and to $7.28 \pm 0.04$ in hypothermic trauma animals at $\mathrm{E}(P<0.05)$. There were no significant differences due to temperatures. Base excess significantly dropped to $-6 \pm$ $0.8 \mathrm{mmol} / \mathrm{L}$ in normothermic trauma animals and down to $-5 \pm 0.9 \mathrm{mmol} / \mathrm{L}$ in hypothermic trauma animals. In sham pigs hypothermia showed more negative base excess than in normothermia. TH produced higher levels of lactate than normothermia at point of time $5.5 \mathrm{hrs}(P<0.05)$. Glycemia undulated within a physiologic range of glucose (in $\mathrm{mg} / \mathrm{dL}$ ) between 70 and $120 \mathrm{mg} / \mathrm{dL}$. Sham pigs showed physiologic values in urinary output. Urinary output started with $214 \pm 58 \mathrm{~mL} / \mathrm{h}$ in normothermic trauma animals and with $160 \pm 46 \mathrm{~mL} / \mathrm{h}$ in hypothermic trauma animals at BL. The urinary output decreased to values of $69 \pm 23 \mathrm{~mL} / \mathrm{h}$ and $40 \pm 8 \mathrm{~mL} / \mathrm{h}$, respectively, after shock. There were no significant differences among hypothermic trauma animals and normothermic trauma animals.

\section{Discussion}

4.1. General. Up to date, thoracic and abdominal trauma with hemorrhagic shock are hazardous risks leading to sepsis and consecutively multiorgan failure (MOF) [27]. Mortality still displays high rates. Therefore, we have previously developed a porcine polytrauma model with settings under realistic conditions [14].

But, do any new therapy strategies exist for intensive care medicine? Thus, we chose to establish a mild therapeutic hypothermia after polytrauma and resuscitation. Our timeline for TH (3 hours) was short as already mentioned above. Due to past examinations on therapeutic hypothermia in animal studies the evidence of the optimal length, duration, and depth of TH is still unanswered [28]. Furthermore as our protocol ended at $15.5 \mathrm{hrs}$ it was not possible to observe clinical outcome after wakening of the animals. But this goal was subsidiary because the acute course of hemodynamics due to TH was of higher interest. The simulated phase of intensive care displayed a very vulnerable phase for the polytrauma patient as chosen for this study $[29,30]$. Most of all we aimed to avoid any interfering effects of TH during hemorrhagic shock [31]. Unfortunately therapeutic hypothermia has rarely been described as a therapy option after polytrauma. Nevertheless the need for a new approach is reasonably high. Clinical and experimental studies have highlighted the delirious impact of accidental hypothermia $(\mathrm{AH})$ on the patients' clinical course [32-36]. On the other side the therapeutic approach of hypothermia got in the focus 


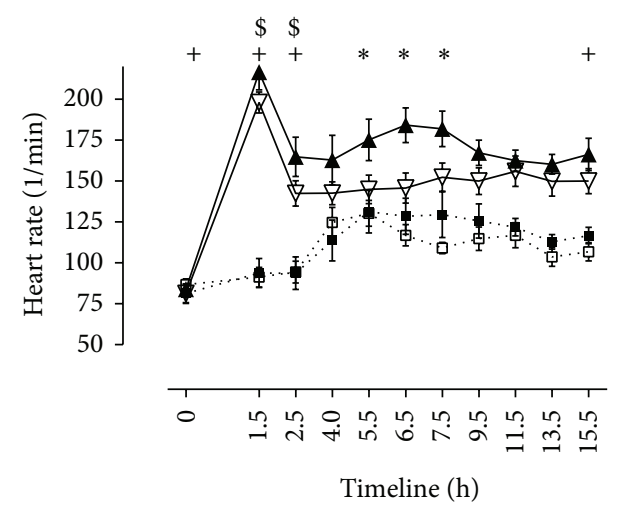

(a)

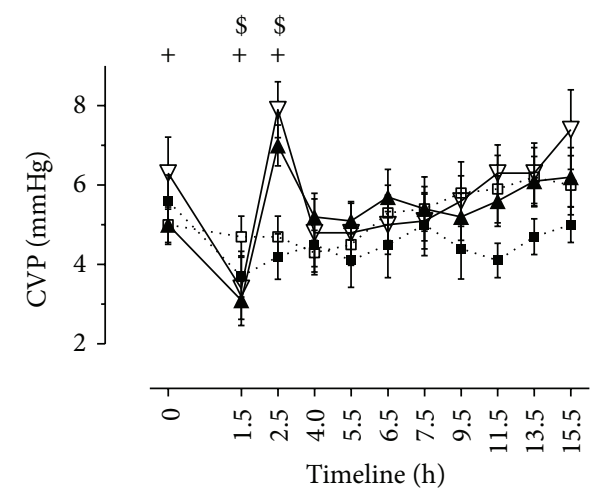

(c)

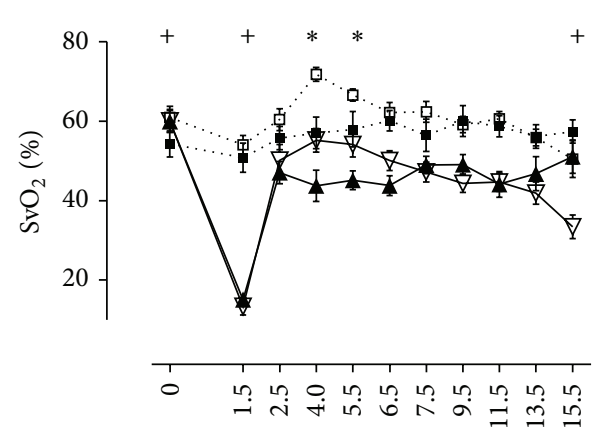

Timeline (h)

(e)

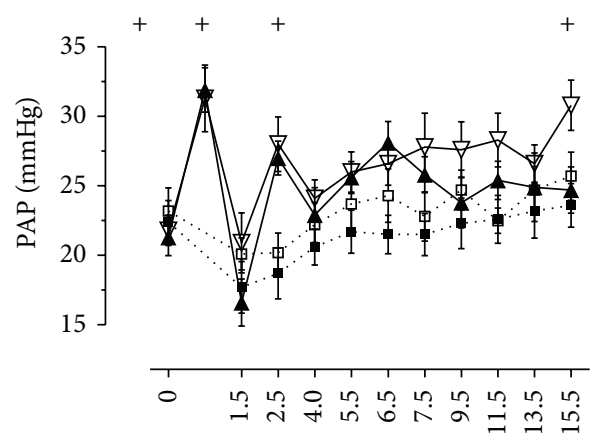

Timeline (h)

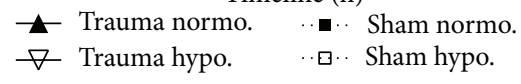

(g)

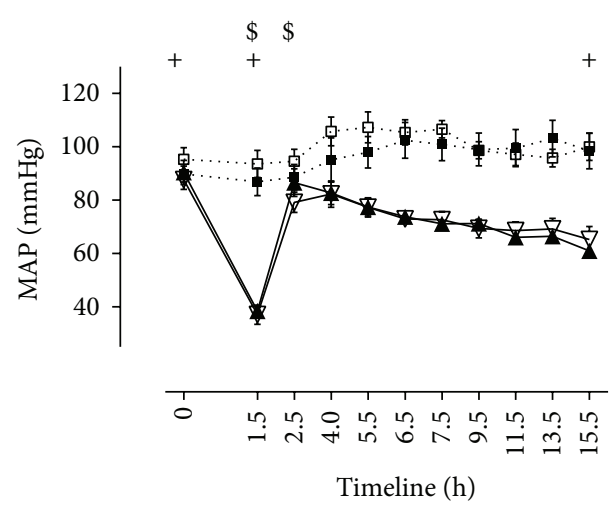

(b)

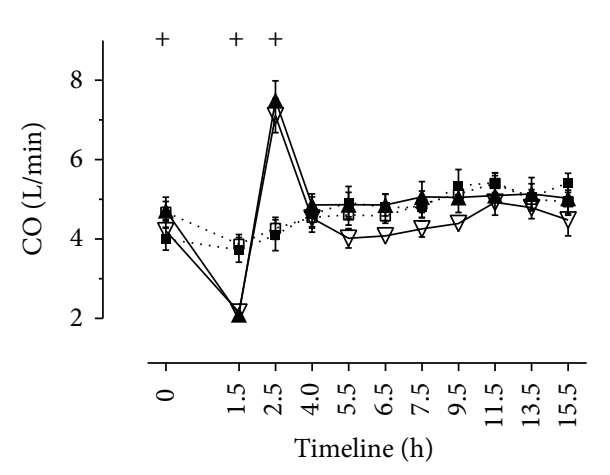

(d)

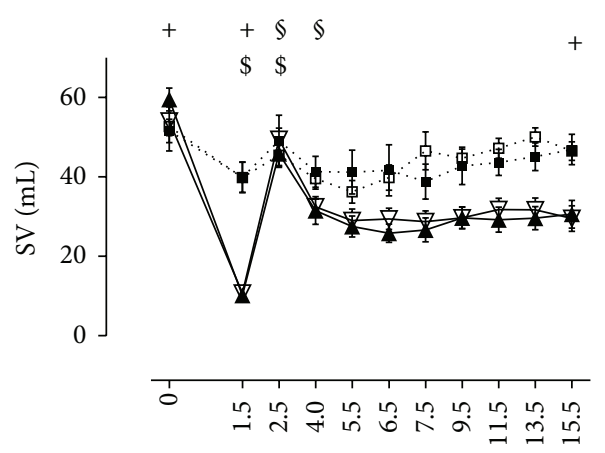

Timeline (h)

(f)

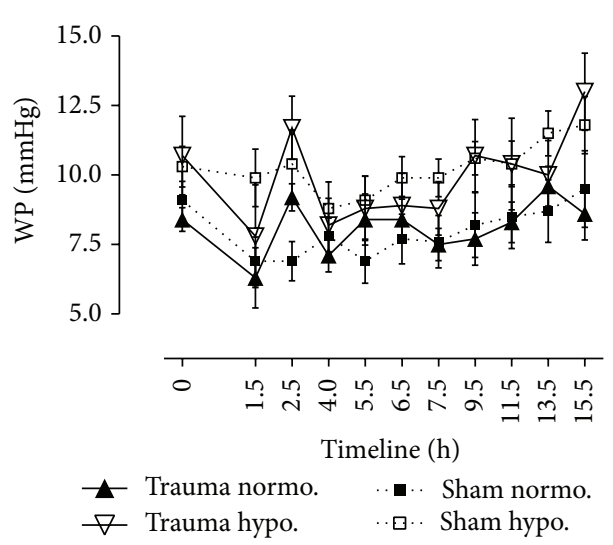

(h)

Figure 2: Continued. 


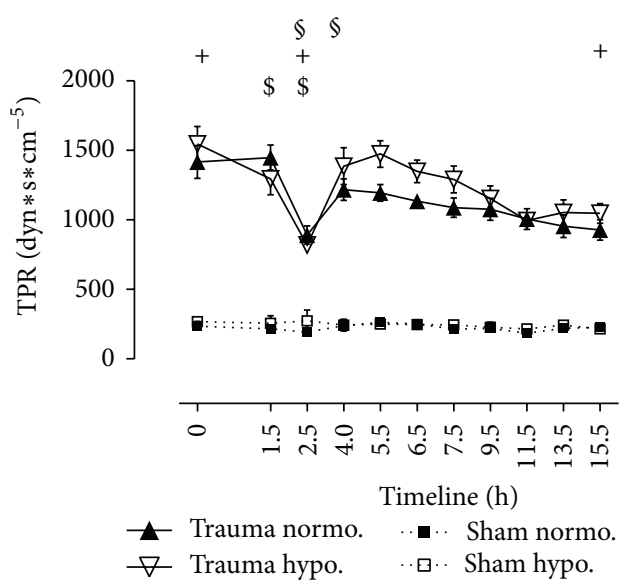

(i)
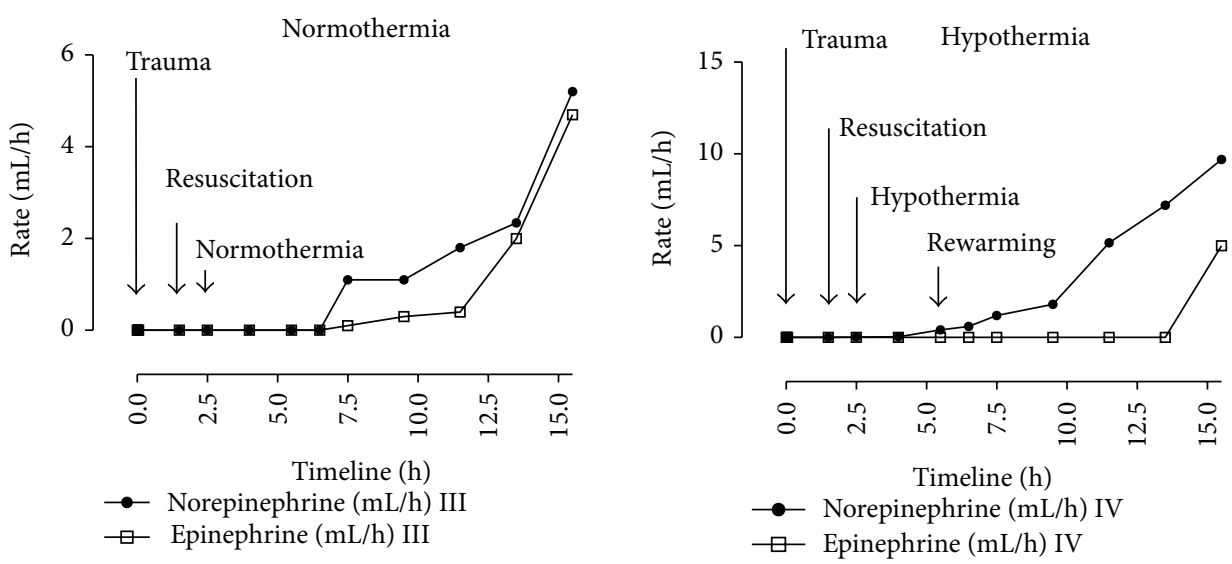

(j)

Figure 2: Normothermic and hypothermic sham animals versus normothermic and hypothermic trauma animals. $N=40$. Timeline 15.5 hrs. Data are shown in mean and standard error of mean. ${ }^{+} P<0.05$, values at $B L$ versus values at $S$ and at $R$ and values at $E$ of trauma pigs $(0,1.5$, 2.5 , and $15.5 \mathrm{hrs}) .{ }^{*} P<0.05$, normothermic versus hypothermic pigs during cooling phase $(4,5.5 \mathrm{hrs}) .{ }^{\$} \mathrm{P}<0.05$, values at $S$ versus values at $\mathrm{R}$ in trauma pigs ( 1.5 and $2.5 \mathrm{hrs}) .{ }^{\$} \mathrm{P}<0.05$, values at $\mathrm{R}$ versus values at $\mathrm{H}$ in trauma pigs ( 2.5 and $4.0 \mathrm{hrs}$ ). (a) Heart rate (HR in $\left.1 / \mathrm{min}\right)$. (b) Mean arterial pressure (MAP in $\mathrm{mmHg}$ ). (c) Central venous pressure (CVP in $\mathrm{mmHg}$ ). (d) Cardiac output (CO in l/min). (e) Mixed venous oxygen saturation $\left(\mathrm{SvO}_{2}\right.$ in \%). (f) Stroke volume (SV in $\mathrm{mL}$ ). (g) Pulmonary artery pressure (PAP in mmHg). (h) Wedge pressure (WP in $\mathrm{mmHg}$ ). (i) TPR (dyn $* \sec * \mathrm{~cm}^{-5}$ ). (j) Norepinephrine and epinephrine in $3 \mathrm{mg} / 50 \mathrm{~mL}$ (in $\mathrm{mL} / \mathrm{h}$ ).

of public interest as recommendations of the International Liaison Committee on Resuscitation had been published dated back in 2002 [1]. Surgical facilities have been performing therapeutic hypothermia (TH) for many years using its tissue protective effects $[3,37]$. Unfortunately full knowledge on beneficial and harmful impact of hypothermia is still lacking. Improved neurological outcome is described due to TH after cardiac arrest $[5,38,39]$. Current literature demonstrates almost equal neurological outcome of unconscious survivors of out-of-hospital cardiac arrest who were treated by either hypo- or normothermia [6]. TH even emerges as a therapeutic approach for traumatic brain injury (TBI) $[4,5]$. In patients with TBI the superior effect is still to be proven because in previous clinical studies groups were small and rather not representative [7]. Furthermore active cooling that is in polytrauma is still under experimental development. Previous investigations on porcine model have shown that environmental hypothermia in hemorrhage and polytrauma has no significant impact on organic and neurological function [40]. Therefore it is of uttermost interest to extend studies concerning therapeutic hypothermia in polytrauma care.

4.2. Temperature. Due to past experiments temperature of $\mathrm{TH}$ is suggested to be between 32 and $34^{\circ} \mathrm{C}$ [41]. Therefore we chose a body core temperature of $34^{\circ} \mathrm{C}$ to follow those recommendations. It has to be considered that the porcine physiologic temperature is higher than in humans $\left(38^{\circ}\right.$ and $\left.39.5^{\circ} \mathrm{C}\right)[24,25]$. We gained the body core temperature by rectal tube which was connected to CoolGard3000/Thermogard $\mathrm{XP}$ as technically required. Other studies preferred temperature measurements by tympanic membrane, bladder, and esophageal or pulmonary catheter. Temperature differences did not vary significantly between rectal and pulmonary artery catheter samples in our study. Furthermore, volume management displays an important role as it can induce $\mathrm{AH}$ [36]. Prewarmed fluids are generally suggested [23]. 


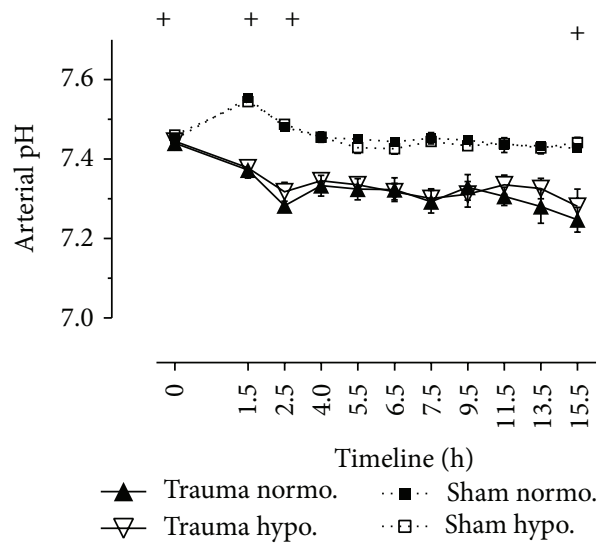

(a)

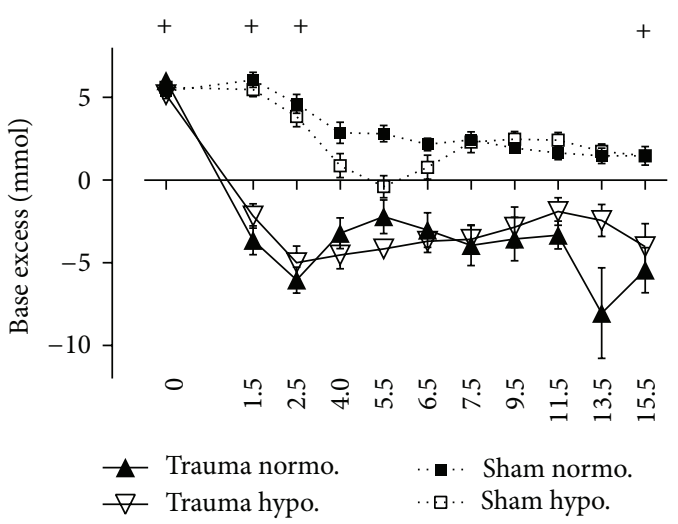

(b)

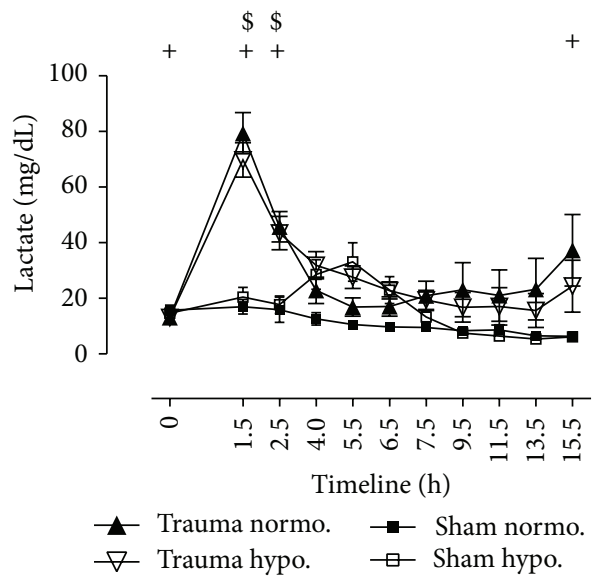

(c)

FIGURE 3: Blood gases and respiratory parameters. Normothermic and hypothermic sham animals versus normothermic and hypothermic trauma animals. $N=40$. Timeline $15.5 \mathrm{hrs}$. Data are shown in mean and standard error of mean. ${ }^{+} P<0.05$, values at $\mathrm{BL}$ versus values at $\mathrm{S}$ and at $\mathrm{R}$ and values at $\mathrm{E}$ of trauma pigs $(0,1.5,2.5$, and $15.5 \mathrm{hrs}) .{ }^{\$} \mathrm{P}<0.05$, values at $\mathrm{S}$ versus values at $\mathrm{R}$ in trauma pigs $(1.5$ and $2.5 \mathrm{hrs}) .{ }^{\S} P<0.05$, values at $\mathrm{R}$ versus values at $\mathrm{H}$ in trauma pigs $(2.5$ and $4.0 \mathrm{hrs}$ ). (a) Arterial $\mathrm{pH}$. (b) Base excess (BE in mmol/L). (c) Lactate in mg/dL.

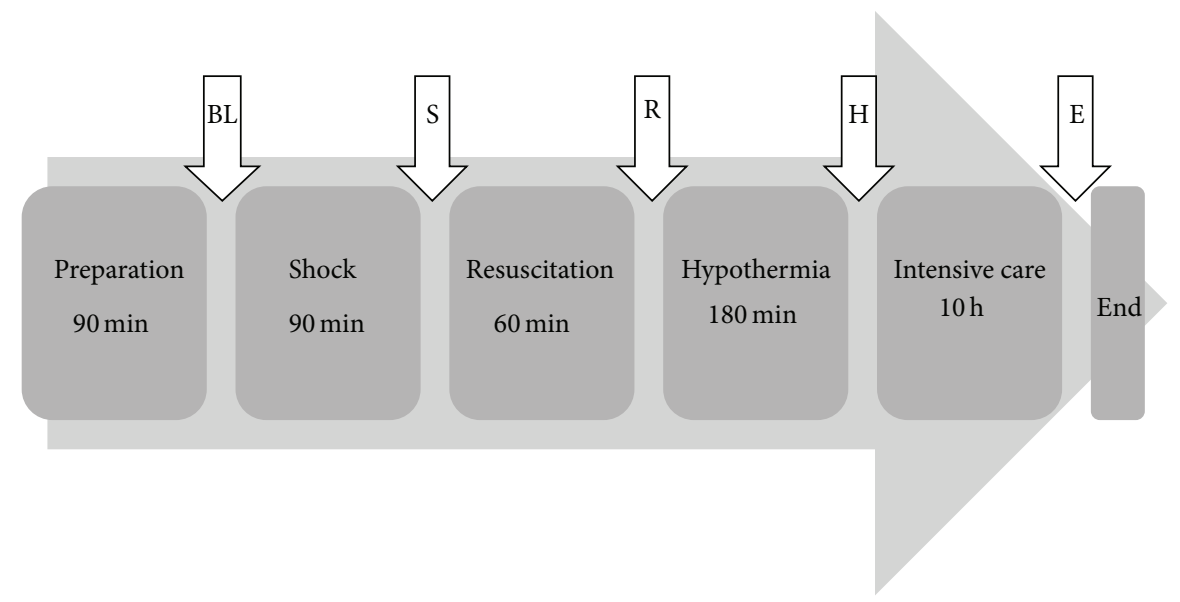

FIgURE 4: Timeline. The timeline of our porcine polytrauma model is displayed. The measurements were performed at several points of time during protocol: at baseline (BL) straight after 90 minutes of preparation, after 90 minutes of shock (S), after 60 minutes of resuscitation (R), after 180 minutes of therapeutic hypothermia (H), and at the end of protocol (E) (15.5 hours after BL). 
Although resuscitation fluids were prewarmed prior to reperfusion in our study, temperature slightly dropped in trauma animals due to resuscitation. TH can be performed in several ways. Yet, no standard method has been succeeded as noninvasive and invasive cooling devices have to be differentiated. We chose an invasive method for cooling (Icy catheter, CoolGard3000/Thermogard XP system). This catheter is inserted percutaneously with an inner circulating water system driven by an external device. It is working safely at a constant rate of cooling. Both in hypothermic sham and in hypothermic trauma animals temperature was reduced down to $34.3 \pm 0.2^{\circ} \mathrm{C}$. Shivering was observed. Rewarming increased body core temperature to physiological levels. Animals remained stable during this period. Sunde et al. reported on similar experiences with endovascular cooling devices [42]. But the extended intraluminal placement of catheters might facilitate inflammatory risks and complications. Other cooling techniques include the infusion of IV cold fluids, which are used in preclinical settings after cardiac arrest and ROSC [43]. Another approach is an extracorporeal system with rapid cooling rates, further supplying oxygen and drugs $[44,45]$. More invasive possibilities are cold peritoneal lavages, intraventricular cerebral hypothermia, and nasal and gastric lavages $[46,47]$. Other studies have used external applications for temperature management, that is, cooling blankets, ice packs, icy fluids, alcohol, and fans [31, 48], which are simple in use but insufficient for targeting temperature [49].

4.3. Hemodynamics. Porcine hemodynamics is comparable to the human system [50]. Several groups have worked on TH during and after hemorrhagic shock [32, 51-56]. Still, the impact of $\mathrm{TH}$ after severe trauma is unknown. We aimed to unfold both beneficial and harmful impacts of TH. Concerning monitoring tools invasive devices such as Swan-Ganz are controversially discussed because of potential surgical bleedings and because of maladapted placements $[57,58]$. We did not observe any complications. Impact of shock was reflected by an increase of HR and decrease of MAP [14] (Figures 2(a)-2(b)). Values of CO and SV dropped significantly after shock. Arterial bloodline and Swan-Ganz balloon catheter continuously documented cardiovascular parameters as early goal-directed therapy decreases morbidity and mortality [16]. Thus, cardiovascular parameters, mainly HR and MAP, improved as mentioned above due to fluid management with colloids and crystalloids in a relation of $12.5 \%$ HES and $87.5 \%$ Ringer according to current trauma guidelines $[3,22]$. Colloids lose their relevance in emergency care, although these components expand plasma volume up to $80 \%[1,4]$. Current discussions (VISEP, 6S, and CHEST) dispute the use of colloids in critically ill patients and the jury is still out as colloids indeed were used in the initial stabilization phases in these studies [59,60]. Due to technical reasons at site we had to abolish shed blood. Nevertheless, cardiovascular parameters adequately improved without the general use of vasopressors or inotropes [61]. Reperfusion led to physiologic values. It is well known that rapid restoration of hemodynamics improves the tissue oxygenation as well as cellular functions $[28,62,63]$. Further to investigate on $\mathrm{TH}$, we accede to past studies that $\mathrm{TH}$ shields cardiac function [31]. Past investigations described increased oxygen concentrations in systemic circulation after TH and hemorrhagic shock [64]. Mild hypothermia has been attributed to show decreased heart rate and decreased cardiac output but an increased vascular resistance. Mean arterial blood pressure and stroke volume are maintained under $\mathrm{TH}$ [41]. We share these findings as HR significantly and CO nonsignificantly decreased in hypothermic trauma animals in comparison to normothermic trauma animals (Figures 2(a) and 2(d)). Most interestingly, mixed venous oxygen saturation was significantly higher in hypothermic trauma animals than in normothermic trauma animals as shown in our experimental approach (Figure 2(e)). But unfortunately $\mathrm{SvO}_{2}$ significantly decreased after rewarming and reached lower values in hypothermic than in normothermic trauma pigs. The mechanism of effective oxygen delivery during $\mathrm{TH}$ is explained by reduced metabolic rates; ATP is preserved [65]. Hypothermia reduces apoptosis and necrosis [8]. Moreover the depth of moderate temperature $\left(34^{\circ} \mathrm{C}\right)$ determines the decrease of myocardial needs while cardiovascular function is stable in our model [31]. Nevertheless lactate values were high in both normo- and hypothermic trauma animals at the end of protocol, which might explain that hypothermic conditions have no positive effect on metabolism at all, at least under this short period of time. The fact of positive inotrope effect due to hypothermia is supported by our findings concerning the stroke volume (SV) which stayed on a lower level in normothermic and hypothermic trauma pigs than in normothermic and hypothermic sham pigs (Figure 2(f)). Our chosen moderate hypothermia provides no increased inotropic effects supported by Meyer and Horton [31]. The systemic vascular resistance (TPR) significantly increased during $\mathrm{TH}$ in relation to normothermic trauma animals. But, interestingly, both normo- and hypothermic sham animals generally stayed on a lower level than trauma animals. There were no differences among normothermic and hypothermic sham animals (Figure 2(i)). We can just assume that the preparation phase might have influenced TPR in its results but this is in contrast to other cardiac parameters, which remain unaffected. After rewarming, values of $\mathrm{SvO}_{2}$ and MAP declined (Figures 2(b) and 2(e)). In addition, the results of blood gases due to hypothermia are of no surprise. Values have to be carefully analyzed as the solubility of blood gases increases when temperature decreases [41].

Another approach of this study which is already published by Mohr et al. [20] was the observation of coagulopathy in porcine model. Unfavorable impact of hypothermia affects the platelet function and harmfully prolongs prothrombin and partial thromboplastin times [66]. Furthermore, we did not observe macroscopically rebleeding potential in our porcine model. Studies on rodent animals have shown that there is a risk of rebleeding due to hypothermia [34]. It has to be known that these findings were conducted under deeper cooling at $30^{\circ} \mathrm{C}$. Generally swine are frequently used in trauma models and they show high stability concerning coagulation pathophysiology [67]. Another fact on coagulopathy due to hemorrhage could be taken from clinical studies on patients who sustained trauma incidences; coagulopathy was 
triggered by several pathways, that is, activation of protein $\mathrm{C}$, malfunction of endothelial borders, platelet dysfunction, and primary and secondary fibrinolysis because of tissue injury. Concepts like damage control resuscitation (DCR) work which includes the transfusion of ratios of fresh frozen plasma (FFP) and red blood cells (RBC) $[68,69]$.

\section{Conclusions}

Our findings suggest that $\mathrm{TH}$ can be safely performed at $34^{\circ} \mathrm{C}$ in a porcine model. $\mathrm{TH}$ was not detrimental for cardiac function in porcine model. Hemodynamics was rather stable during $\mathrm{TH}$. Interestingly, $\mathrm{TH}$ provides hints for tissue protective impact. Values of $\mathrm{SvO}_{2}$ were high during TH. But, presumably, length and depth of $\mathrm{TH}$ were not intensive enough to clearly substantiate the advantages and disadvantages of TH. Further studies should extend the duration of $\mathrm{TH}$.

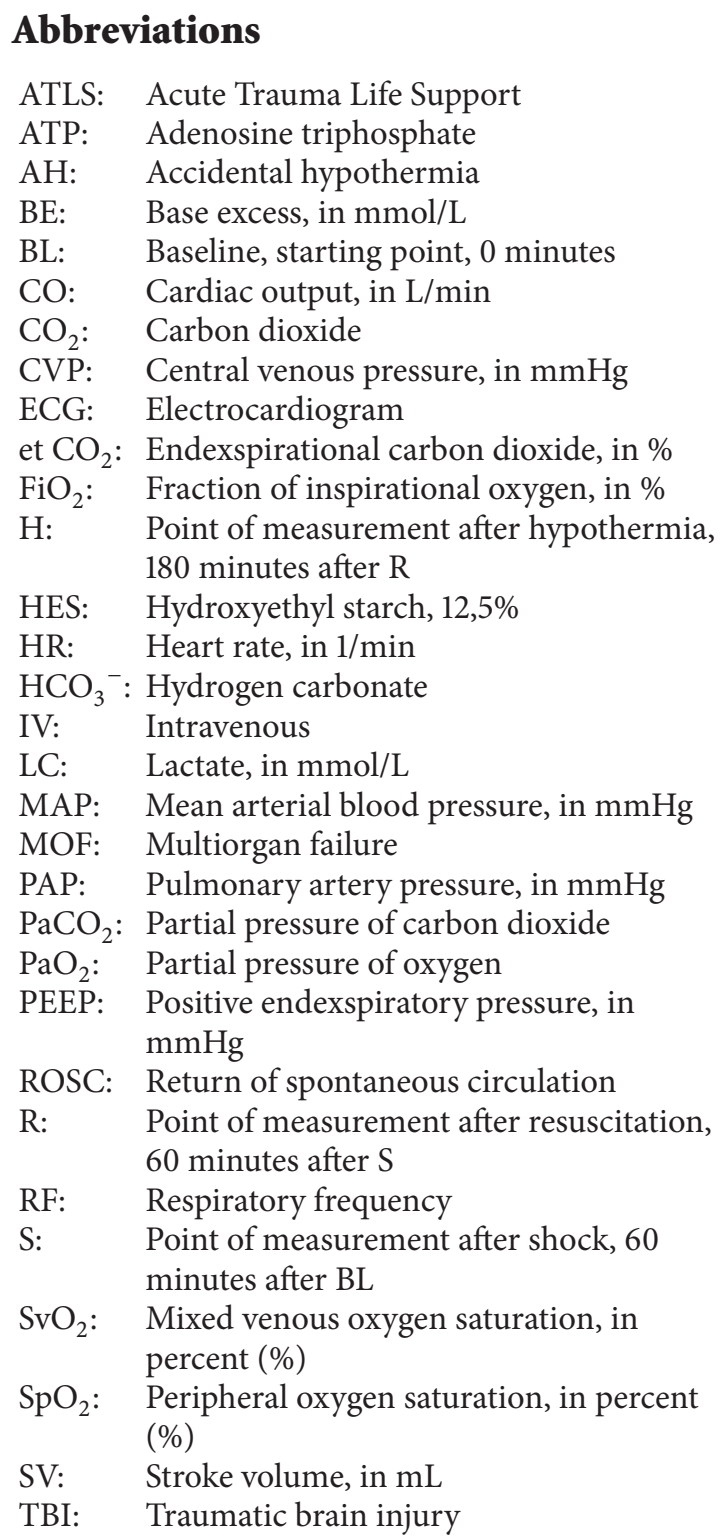

TH: Therapeutic hypothermia, here defined as temperature in $34^{\circ}$ Celsius

TPR: Total peripheral concentration

Vt: Tidal volume, in $\mathrm{mL}$

WP: Wedge pressure, in $\mathrm{mmHg}$.

\section{Conflict of Interests}

The authors declare that they have no conflict of interests.

\section{Authors' Contribution}

Each author listed above contributed to this study in significant matter. Matthias Weuster, Philipp Mommsen, Juliane Mohr, Matthias Fröhlich, and Ingo Witte continuously worked as medical residents on the experiments on site. They were daily supervised by Claudia Keibl as the veterinarian and by Martijn van Griensven as the head of study on site. This trauma protocol was originally designed within the Committee on Emergency Medicine, Intensive Care and Trauma Management (Section "NIS") of the German Society for Trauma Surgery (DGU).

\section{Acknowledgments}

This work was supported by the Else-Kroener-FreseniusStiftung, Grant no. 2009 A12. The authors would like to thank Karl Kropik, Mohammad Jafarmadar, Anna Khadem, and Karin Hahn at Ludwig Boltzmann Institute for Experimental and Clinical Traumatology, Vienna, Austria, for their excellent technical support.

\section{References}

[1] M. Holzer, F. Sterz, J. M. Darby et al., "Mild therapeutic hypothermia to improve the neurologic outcome after cardiac arrest," The New England Journal of Medicine, vol. 346, no. 8, pp. 549-556, 2002.

[2] I. W. Brown Jr., W. W. Smith, W. G. Young Jr., and W. C. Sealy, "Experimental and clinical studies of controlled hypothermia rapidly produced and corrected by a blood heat exchanger during extracorporeal circulation," The Journal of Thoracic Surgery, vol. 36, no. 4, pp. 497-505, 1958.

[3] P. M. Hellings, "Controlled hypothermia; recent developments in the use of hypothermia in neurosurgery," British Medical Journal, vol. 2, no. 5092, pp. 346-350, 1958.

[4] S. Mrozek, F. Vardon, and T. Geeraerts, "Brain temperature: physiology and pathophysiology after brain injury," Anesthesiology Research and Practice, vol. 2012, Article ID 989487, 13 pages, 2012.

[5] H. Ma, B. Sinha, R. S. Pandya et al., “Therapeutic hypothermia as a neuroprotective strategy in neonatal hypoxic-ischemic brain injury and traumatic brain injury," Current Molecular Medicine, vol. 12, no. 10, pp. 1282-1296, 2012.

[6] N. Nielsen, J. Wetterslev, T. Cronberg et al., "Targeted temperature management at $33^{\circ} \mathrm{C}$ versus $36^{\circ} \mathrm{C}$ after cardiac arrest," The New England Journal of Medicine, vol. 369, no. 23, pp. 2197-2206, 2013.

[7] G. L. Clifton, A. Valadka, D. Zygun et al., "Very early hypothermia induction in patients with severe brain injury (the National 
Acute Brain Injury Study: Hypothermia II): a randomised trial," The Lancet Neurology, vol. 10, no. 2, pp. 131-139, 2011.

[8] S. A. Tisherman, "Hypothermia and injury," Current Opinion in Critical Care, vol. 10, no. 6, pp. 512-519, 2004.

[9] P. Mommsen, H. Andruszkow, C. Frömke et al., "Effects of accidental hypothermia on posttraumatic complications and outcome in multiple trauma patients," Injury, vol. 44, no. 1, pp. 86-90, 2013.

[10] A. S. Wolberg, Z. H. Meng, D. M. Monroe III, and M. Hoffman, "A systematic evaluation of the effect of temperature on coagulation enzyme activity and platelet function," Journal of Trauma-Injury, Infection and Critical Care, vol. 56, no. 6, pp. 1221-1228, 2004.

[11] K. D. Craven, L. Oppenheimer, and L. D. H. Wood, "Effects of contusion and flail chest on pulmonary perfusion and oxygen exchange," Journal of Applied Physiology: Respiratory, Environmental and Exercise Physiology, vol. 47, no. 4, pp. 729737, 1979.

[12] G. C. Clark, W. P. Schecter, and D. D. Trunkey, "Variables affecting outcome in blunt chest trauma: flail chest vs. pulmonary contusion," Journal of Trauma, vol. 28, no. 3, pp. 298-304, 1988.

[13] S. Huber-Wagner, M. Qvick, T. Mussack et al., "Massive blood transfusion and outcome in 1062 polytrauma patients: a prospective study based on the Trauma Registry of the German Trauma Society," Vox Sanguinis, vol. 92, no. 1, pp. 69-78, 2007.

[14] F. Hildebrand, M. Weuster, P. Mommsen et al., "A combined trauma model of chest and abdominal trauma with hemorrhagic shock-description of a new porcine model," Shock, vol. 38, no. 6, pp. 664-670, 2012.

[15] M. Hadian and M. R. Pinsky, "Evidence-based review of the use of the pulmonary artery catheter: impact data and complications," Critical Care, vol. 10, supplement 3, article S8, 2006.

[16] E. Rivers, B. Nguyen, S. Havstad et al., "Early goal-directed therapy in the treatment of severe sepsis and septic shock," The New England Journal of Medicine, vol. 345, no. 19, pp. 1368-1377, 2001.

[17] L. Bossaert, R. E. O’Connor, H.-R. Arntz et al., "Part 9: acute coronary syndromes: 2010 international consensus on cardiopulmonary resuscitation and emergency cardiovascular care science with treatment recommendations," Resuscitation, vol. 81, supplement 1, pp. e175-e212, 2010.

[18] W. D. Dietrich and H. M. Bramlett, "The evidence for hypothermia as a neuroprotectant in traumatic brain injury," Neurotherapeutics, vol. 7, no. 1, pp. 43-50, 2010.

[19] M. Fröhlich, F. Hildebrand, M. Weuster et al., "Induced hypothermia reduces the hepatic inflammatory response in a swine multiple trauma model," Journal of Trauma and Acute Care Surgery, vol. 76, no. 6, pp. 1425-1432, 2014.

[20] J. Mohr, S. Ruchholtz, F. Hildebrand et al., "Induced hypothermia does not impair coagulation system in a swine multiple trauma model," Journal of Trauma and Acute Care Surgery, vol. 74, no. 4, pp. 1014-1020, 2013.

[21] M. S. Englehart, C. E. Allison, B. H. Tieu et al., "Ketamine-based total intravenous anesthesia versus isoflurane anesthesia in a swine model of hemorrhagic shock," Journal of Trauma-Injury, Infection and Critical Care, vol. 65, no. 4, pp. 901-908, 2008.

[22] J. A. Cade and M. Truesdale, "Preferences of critical care registrars in fluid resuscitation of major trauma patients: concordance with current guidelines," Anaesthesia and Intensive Care, vol. 39, no. 2, pp. 262-267, 2011.
[23] J. B. Kortbeek, S. A. Al Turki, J. Ali et al., "Advanced trauma life support, 8th edition, the evidence for change," The Journal of Trauma, vol. 64, no. 6, pp. 1638-1650, 2008.

[24] D. J. Duncker, C. L. Klassen, Y. Ishibashi, S. H. Herrlinger, T. J. Pavek, and R. J. Bache, "Effect of temperature on myocardial infarction in swine," The American Journal of Physiology-Heart and Circulatory Physiology, vol. 270, no. 4, pp. H1189-H1199, 1996.

[25] M. Holzer, S. A. Bernard, S. Hachimi-Idrissi, R. O. Roine, F. Sterz, and M. Müllner, "Hypothermia for neuroprotection after cardiac arrest: systematic review and individual patient data meta-analysis," Critical Care Medicine, vol. 33, no. 2, pp. 414418, 2005.

[26] R. Durham, K. Neunaber, G. Vogler et al., "Right ventricular end-diastolic volume as a measure of preload," Journal of Trauma-Injury, Infection and Critical Care, vol. 39, no. 2, pp. 218-224, 1995.

[27] W. G. DeLong Jr. and C. T. Born, "Cytokines in patients with polytrauma," Clinical Orthopaedics and Related Research, no. 422, pp. 57-65, 2004.

[28] M. E. George, K. E. Mulier, and G. J. Beilman, "Hypothermia is associated with improved outcomes in a porcine model of hemorrhagic shock," The Journal of Trauma-Injury, Infection \& Critical Care, vol. 68, no. 3, pp. 662-668, 2010.

[29] M. Fröhlich, R. Lefering, C. Probst et al., "Epidemiology and risk factors of multiple-organ failure after multiple trauma: an analysis of 31,154 patients from the TraumaRegister DGU," Journal of Trauma and Acute Care Surgery, vol. 76, no. 4, pp. 921-927, 2014.

[30] A. Takasu, P. Carrillo, S. W. Stezoski, P. Safar, and S. A. Tisherman, "Mild or moderate hypothermia but not increased oxygen breathing prolongs survival during lethal uncontrolled hemorrhagic shock in rats, with monitoring of visceral dysoxia," Critical Care Medicine, vol. 27, no. 8, pp. 1557-1564, 1999.

[31] D. M. Meyer and J. W. Horton, "Effect of different degrees of hypothermia on myocardium in treatment of hemorrhagic shock," Journal of Surgical Research, vol. 48, no. 1, pp. 61-67, 1990.

[32] G. J. Beilman, J. J. Blondet, T. R. Nelson et al., "Early hypothermia in severely injured trauma patients is a significant risk factor for multiple organ dysfunction syndrome but not mortality," Annals of Surgery, vol. 249, no. 5, pp. 845-850, 2009.

[33] L. M. Gentilello, G. J. Jurkovich, M. S. Stark, S. A. Hassantash, and G. E. O'Keefe, "Is hypothermia in the victim of major trauma protective or harmful? A randomized, prospective study," Annals of Surgery, vol. 226, no. 4, pp. 439-449, 1997.

[34] G. Heinius, R. G. Hahn, and A. Sondén, "Hypothermia increases rebleeding during uncontrolled hemorrhage in the rat," Shock, vol. 36, no. 1, pp. 60-66, 2011.

[35] F. Hildebrand, M. van Griensven, P. Giannoudis et al., "Impact of hypothermia on the immunologic response after trauma and elective surgery," Surgical Technology International, vol. 14, pp. 41-50, 2005.

[36] P. Kobbe, P. Lichte, M. Wellmann et al., "Impact of hypothermia on the severely injured patient," Unfallchirurg, vol. 112, no. 12, pp. 1055-1061, 2009.

[37] F. Hildebrand, P. V. Giannoudis, M. van Griensven, M. Chawda, and H.-C. Pape, "Pathophysiologic changes and effects of hypothermia on outcome in elective surgery and trauma patients," American Journal of Surgery, vol. 187, no. 3, pp. 363371, 2004. 
[38] M. Haugk, C. Testori, F. Sterz et al., "Relationship between time to target temperature and outcome in patients treated with therapeutic hypothermia after cardiac arrest," Critical Care, vol. 15, no. 2, article R101, 2011.

[39] E. A. Sailhamer, Z. Chen, N. Ahuja et al., "Profound hypothermic cardiopulmonary bypass facilitates survival without a high complication rate in a swine model of complex vascular, splenic, and colon injuries," Journal of the American College of Surgeons, vol. 204, no. 4, pp. 642-653, 2007.

[40] U. P. Iyegha, J. J. Greenberg, K. E. Mulier, J. Chipman, M. George, and G. J. Beilman, "Environmental hypothermia in porcine polytrauma and hemorrhagic shock is safe," Shock, vol. 38, no. 4, pp. 387-394, 2012.

[41] S. A. Bernard and M. Buist, "Induced hypothermia in critical care medicine: a review," Critical Care Medicine, vol. 31, no. 7, pp. 2041-2051, 2003.

[42] K. Sunde, E. Søoreide, D. Jacobsen, and P. A. Steen, “Therapeutic hypothermia after cardiac arrest saves more lives," Tidsskrift for den Norske Laegeforening, vol. 124, no. 7, pp. 925-926, 2004.

[43] I. Virkkunen, A. Yli-Hankala, and T. Silfvast, "Induction of therapeutic hypothermia after cardiac arrest in prehospital patients using ice-cold Ringer's solution: a pilot study," Resuscitation, vol. 62, no. 3, pp. 299-302, 2004.

[44] M. M. Zviman, A. Roguin, A. Jacobs, K. Rent, A. Lardo, and H. R. Halperin, "A new method for inducing hypothermia during cardiac arrest," Critical Care Medicine, vol. 32, supplement 9, pp. S369-S373, 2004.

[45] P. J. Safar and P. M. Kochanek, "Therapeutic hypothermia after cardiac arrest," The New England Journal of Medicine, vol. 346, no. 8, pp. 612-613, 2002.

[46] M. N. Diringer, "Treatment of fever in the neurologic intensive care unit with a catheter-based heat exchange system," Critical Care Medicine, vol. 32, no. 2, pp. 559-564, 2004.

[47] K. Mori, J. Saito, Y. Kurata et al., "Rapid development of brain hypothermia using femoral-carotid bypass," Academic Emergency Medicine, vol. 8, no. 4, pp. 303-308, 2001.

[48] A. Takasu, S. Ishihara, H. Anada, T. Sakamoto, and Y. Okada, "Surface cooling, which falls to reduce the core temperature rapidly, hastens death during severe hemorrhagic shock in pigs," The Journal of Trauma-Injury, Infection \& Critical Care, vol. 48, no. 5, pp. 942-947, 2000.

[49] A. A. Konstas, M. A. Neimark, A. F. Laine, and J. Pile-Spellman, "A theoretical model of selective cooling using intracarotid cold saline infusion in the human brain," Journal of Applied Physiology, vol. 102, no. 4, pp. 1329-1340, 2007.

[50] S. D. Cho, J. B. Holcomb, B. H. Tieu et al., "Reproducibility of an animal model simulating complex combat-related injury in a multiple-institution format," Shock, vol. 31, no. 1, pp. 87-96, 2009.

[51] H. B. Alam, Z. Chen, K. Honma et al., "The rate of induction of hypothermic arrest determines the outcome in a swine model of lethal hemorrhage," Journal of Trauma-Injury, Infection and Critical Care, vol. 57, no. 5, pp. 961-969, 2004.

[52] H. B. Alam, M. Duggan, Y. Li et al., "Putting life on hold-for how long? Profound hypothermic cardiopulmonary bypass in a Swine model of complex vascular injuries," Journal of Trauma, vol. 64, no. 4, pp. 912-922, 2008.

[53] M. Arlt, A. Philipp, S. Voelkel et al., "Extracorporeal membrane oxygenation in severe trauma patients with bleeding shock," Resuscitation, vol. 81, no. 7, pp. 804-809, 2010.
[54] R. A. Finkelstein and H. B. Alam, "Induced hypothermia for trauma: current research and practice," Journal of Intensive Care Medicine, vol. 25, no. 4, pp. 205-226, 2010.

[55] S. A. Tisherman, A. Rodriguez, and P. Safar, "Therapeutic hypothermia in traumatology," The Surgical Clinics of North America, vol. 79, no. 6, pp. 1269-1289, 1999.

[56] X. Wu, P. M. Kochanek, K. Cochran et al., "Mild hypothermia improves survival after prolonged, traumatic hemorrhagic shock in pigs," Journal of Trauma-Injury, Infection and Critical Care, vol. 59, no. 2, pp. 291-301, 2005.

[57] G. Hartmann, A. Steib, B. Ludes, and J. Ravanello, "Pulmonary artery rupture due to Swan-Ganz catheters," Annales Francaises d'Anesthesie et de Reanimation, vol. 7, no. 6, pp. 486-493, 1988.

[58] G. Barmparas, K. Inaba, C. Georgiou et al., "Swan-ganz catheter use in trauma patients can be reduced without negatively affecting outcomes," World Journal of Surgery, vol. 35, no. 8, pp. 1809-1817, 2011.

[59] D. Chappell and M. Jacob, "Hydroxyethyl starch-the importance of being earnest," Scandinavian Journal of Trauma, Resuscitation and Emergency Medicine, vol. 21, no. 1, article 61, 2013.

[60] D. Chappell and M. Jacob, "Twisting and ignoring facts on hydroxyethyl starch is not very helpful," Scandinavian Journal of Trauma, Resuscitation and Emergency Medicine, vol. 21, no. 1, article 85, 2013.

[61] N. Gasparetto, L. Cacciavillani, and S. Valente, "The accuracy of PiCCO measurements in hypothermic post-cardiac arrest patients," Anaesthesia, vol. 67, no. 9, pp. 1050-1051, 2012.

[62] D. Crippen, P. Safar, L. Porter, and J. Zone, "Improved survival of hemorrhagic shock with oxygen and hypothermia in rats," Resuscitation, vol. 21, no. 2-3, pp. 271-281, 1991.

[63] S.-H. Kim, S. W. Stezoski, P. Safar, A. Capone, and S. Tisherman, "Hypothermia and minimal fluid resuscitation increase survival after uncontrolled hemorrhagic shock in rats," Journal of Trauma, vol. 42, no. 2, pp. 213-222, 1997.

[64] A. Wladis, H. Hjelmqvist, B. Brismar, and B. T. Kjellström, "Acute metabolic and endocrine effects of induced hypothermia in hemorrhagic shock: an experimental study in the pig," Journal of Trauma-Injury, Infection and Critical Care, vol. 45, no. 3, pp. 527-533, 1998.

[65] A. Seekamp, F. Hildebrand, M. Van Griensven, M. Grotz, and H. Tscherne, "Adenosine-triphosphate (ATP) in accidental and elective hypothermia," Zentralblatt fur Chirurgie, vol. 124, no. 11, pp. 1017-1029, 1999.

[66] A. Zeiner, M. Holzer, F. Sterz et al., "Mild resuscitative hypothermia to improve neurological outcome after cardiac arrest: a clinical feasibility trial," Stroke, vol. 31, no. 1, pp. 86-94, 2000.

[67] H. B. Alam, K. B. Hamwi, M. Duggan et al., "Hemostatic and pharmacologic resuscitation: results of a long-term survival study in a swine polytrauma model," Journal of Trauma-Injury, Infection and Critical Care, vol. 70, no. 3, pp. 636-645, 2011.

[68] K. Duan, W. Yu, and N. Li, "The pathophysiology and management of acute traumatic coagulopathy," Clinical and Applied Thrombosis/Hemostasis, 2013.

[69] H. Schöchl, A. Grassetto, and C. J. Schlimp, "Management of hemorrhage in trauma," Journal of Cardiothoracic and Vascular Anesthesia, vol. 27, no. 4, pp. S35-S43, 2013. 


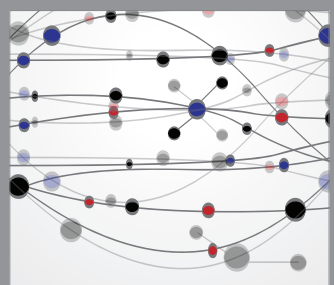

The Scientific World Journal
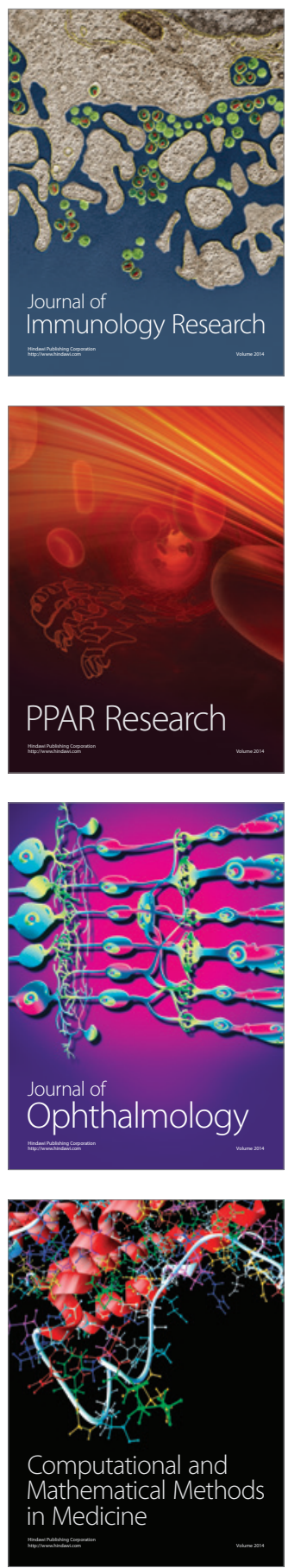

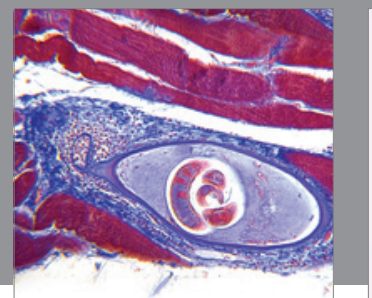

Gastroenterology

Research and Practice
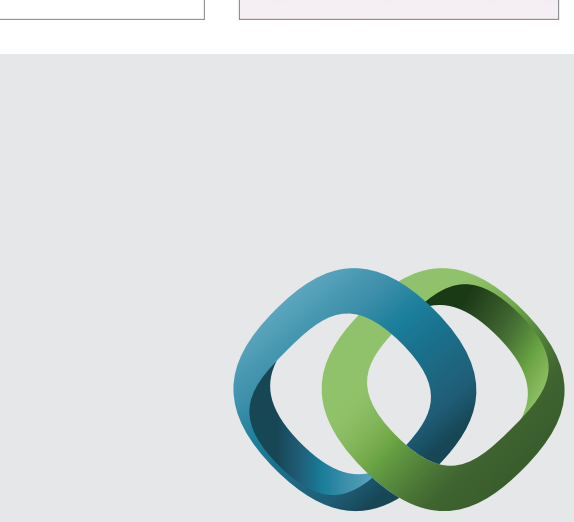

\section{Hindawi}

Submit your manuscripts at

http://www.hindawi.com
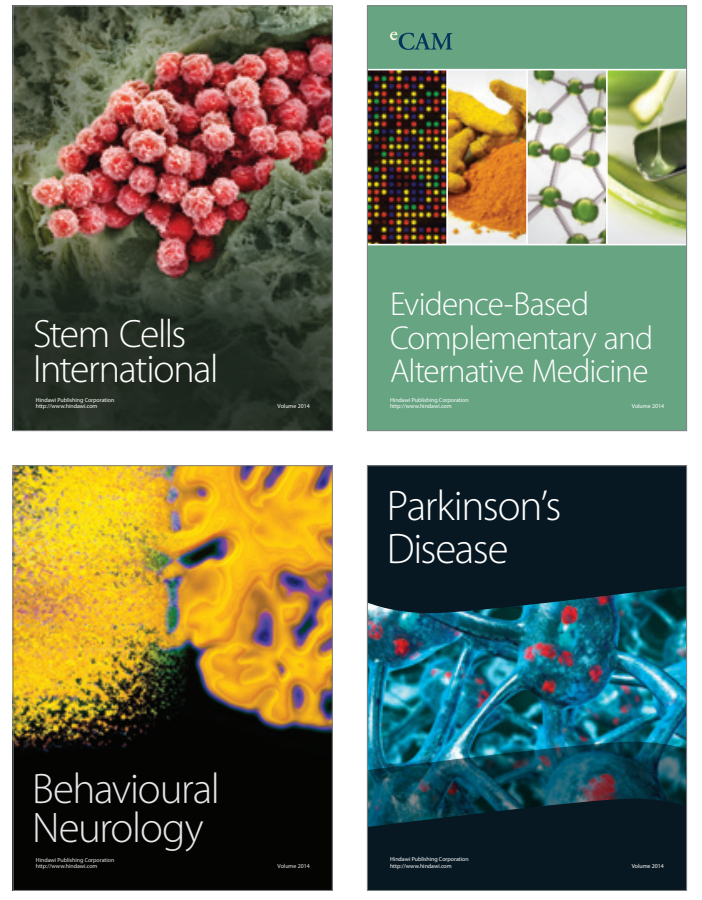
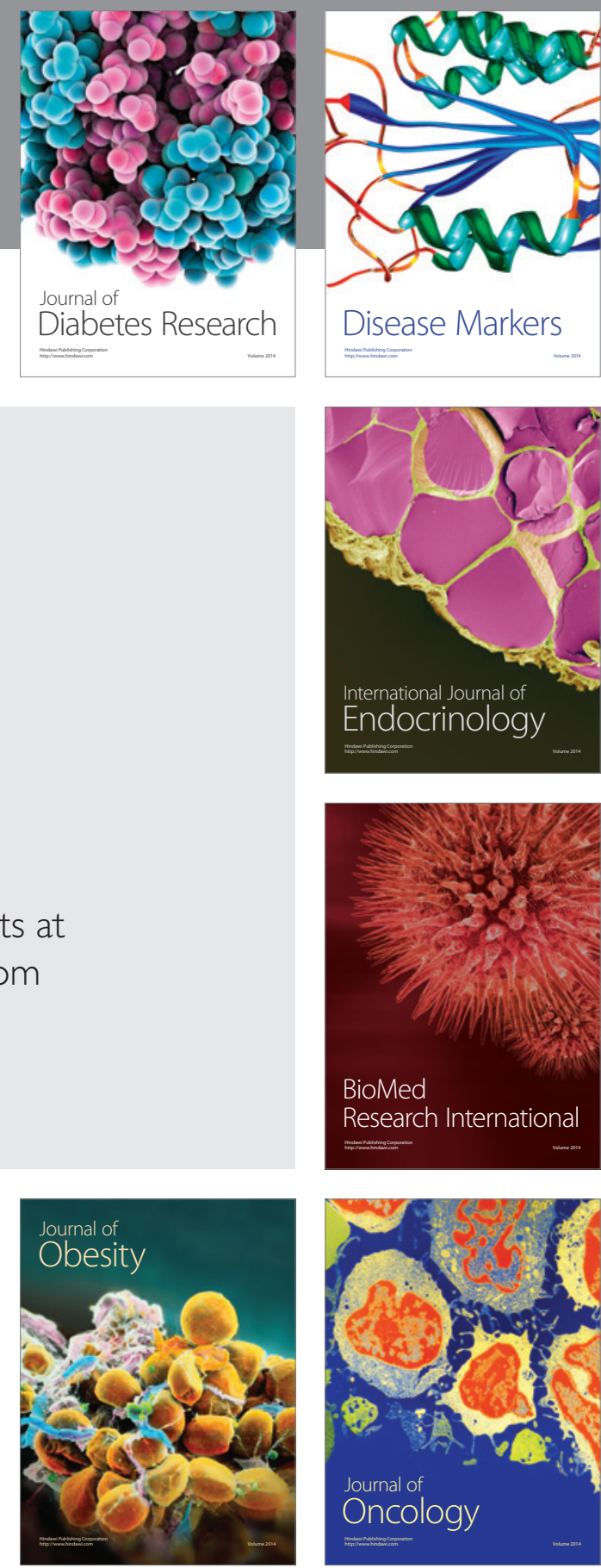

Disease Markers
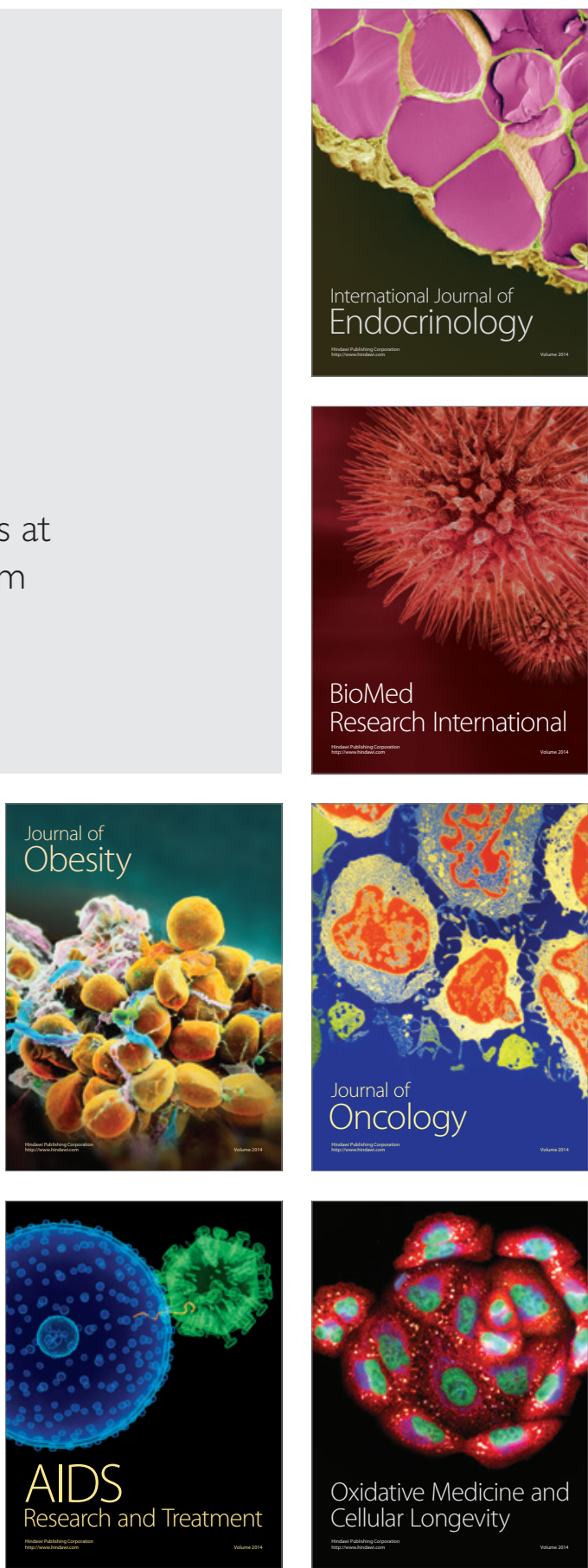